\title{
Trabalho e ação sindical em redes globais de produção'
}

José Ricardo Ramalho e Rodrigo Salles Pereira dos Santos

Introdução

Reconhecer e investigar o papel do trabalho em uma sociedade capitalista articulada globalmente tornou-se um verdadeiro desafio para os cientistas sociais. Mudanças significativas nos processos produtivos, ocorridos nos últimos quarenta anos, afetaram o perfil dos trabalhadores, fragilizaram os laços de emprego e intimidaram os órgãos de representação política dos trabalhadores. Legislações de proteção laboral foram gradativamente reconfiguradas em função das demandas corporativas e estatais por flexibilidade como eixo de estratégias corporativas e de políticas de desenvolvimento.

Nesse processo, a expansão do alcance geográfico das atividades empresariais e a reconfiguração organizacional da produção sob a forma de sistemas transnacionais reconstituíram de forma dramática a eficácia dos recursos e formas de exercício do poder dos trabalhadores e suas organizações de representação em várias escalas.

Desde então, diferentes perspectivas teóricas - em boa medida, interdisciplinares - foram desenvolvidas de modo a dar conta dos processos e impactos provocados pelo capitalismo contemporâneo global. Entre as mais destacadas estão aquelas que construíram modelos interpretativos tomando como base a constituição de sistemas transnacionais de produção (sTPs), ao enfatizar, em variadas escalas, estratégias

1. Este artigo se beneficia de dados e bibliografia de projetos de pesquisa apoiados pelo cNPq e pela Faperj. 
corporativas dispersas espacialmente, embora integradas sob o ponto de vista da funcionalidade de seus processos de acumulação.

Não obstante, considerando que as estratégias corporativas só se materializam através de interações assimétricas com agentes políticos e sociais, nossa intenção é demonstrar a necessidade da integração do trabalho e da ação sindical nos modelos de interpretação acerca da ação econômica coordenada por corporações transnacionais (CTNS), identificando novos mecanismos de contestação às formas de acumulação de capital. Em particular, este artigo busca realizar um balanço da incorporação da temática do trabalho na abordagem das redes globais de produção (RGPs), discutindo seus limites analíticos e demonstrando seu potencial para uma compreensão relacional do conflito capital-trabalho.

Esquematicamente, além desta seção introdutória, o texto se divide em quatro seções. Em primeiro lugar, apresentamos a abordagem das RGPs a partir das dimensões das relações interfirma e multiagente, destacando suas principais ferramentas analíticas, reunidas em torno dos conceitos de valor, poder e enraizamento. A seção seguinte enfoca as lacunas do modelo quanto à incorporação dos trabalhadores e apresenta um panorama da evolução recente dos principais trabalhos empíricos inspirados por essa concepção. Finalmente, o artigo situa o debate recente sobre o papel dos sindicatos e das novas formas de organização da ação coletiva dos trabalhadores como constituintes da globalização econômica, pretendendo contribuir para um entendimento das RGPs como redes propriamente laborais. A seção conclusiva resume o debate, apresentando seus desafios e potenciais desenvolvimentos futuros.

\section{Corporações transnacionais e redes globais de produção}

A partir de meados dos anos 1980 (Granovetter, 1985), a noção de rede passou a integrar o equipamento conceitual das ciências sociais. No que diz respeito à globalização econômica e suas relações com o mundo do trabalho, tal noção passou a ser decisiva na investigação da diversidade organizacional e abrangência geográfica crescente das firmas (Gereffi e Korzeniewicz, 1994; Dicken, 2010) e de seus impactos sobre os padrões de ação coletiva dos trabalhadores, crescentemente estruturados sob formatos internacionalizados (Mello e Silva et al., 2015; Rombaldi, 2016).

Considerando as diferentes expressões da transformação dos processos socioeconômicos sob a globalização, sua incorporação como artefato analítico parece refletir uma inflexão da natureza contemporânea das relações entre capital e trabalho, no que diz respeito às relações interfirma e intersindicais e às interações entre esses conjuntos de agentes sociais e econômicos. Nesses termos, estaríamos “testemunhando o surgimento [e a consolidação] de redes de produção globais (RPGs)” (Dicken, 2010, p. 38). 
Segundo os formuladores dessa perspectiva, as redes globais de produção (RGPs) abrangem o

[... nexo de funções e operações interligadas através das quais bens e serviços são produzidos, distribuídos e consumidos [...] [tendo se tornado] organizacionalmente mais complexas quanto cada vez mais globais em sua extensão geográfica. Essas redes não apenas integram firmas (e partes de firmas) em estruturas que obscurecem fronteiras organizacionais tradicionais - por meio do desenvolvimento de diversas formas de relações de equidade e não equidade -, mas também integram economias nacionais (ou partes dessas economias) de formas que possuem implicações colossais para seu bem-estar (Henderson et al., 2011, p. 153).

Em um sentido propriamente sociológico, RGPs constituem sistemas transnacionais híbridos de coordenação da ação social de tipo econômico, combinando, de um lado, relações "estritamente" econômicas (Weber, 2006) que integram firmas (relações interfirma) a arranjos de controle independentes de propriedade (Gereffi et al., 2005) e, de outro, relações economicamente condicionadas e/ou relevantes (Weber, 2006), isto é, estabelecidas entre agentes econômicos e não econômicos (Santos, 2011).

A dimensão das relações interfirma ${ }^{2}$ enfoca as interações competitivas e/ou cooperativas no âmbito da economia "estrita". Embora integrados em mercados e setores específicos e, portanto, sujeitos a relações mais abrangentes, os agentes econômicos em rede constituem um ambiente relacional específico, caracterizado por assimetrias de recursos (poder), padrões de comportamento (enraizamento) e estratégias corporativas (valor) diversificados.

Em primeiro lugar, retomando a temática da coordenação, RGPs são conformadas e controladas por agentes econômicos coletivos racionais - ainda que em sentido restrito - cujo objetivo chave é o valor. A abordagem das RGPs concebe o valor como o resultado do processo de trabalho stricto sensu, que responderia por sua criação, combinado a formas de renda específicas (tecnológica, organizacional, relacional, de marca ou de política comercial), o que determinaria as condições de ampliação e captura de valor.

Em sentido prático, a formação do valor se desloca do interior da organização vertical integrada e se "espalha" na rede, de modo que CTNs configuram e lideram RGPs com o objetivo de criar, expandir e apropriar-se do valor criado por outras firmas integrantes da rede ${ }^{3}$. Nesse sentido, a reorientação estratégica das CTNs para

2. Em grande medida, essa dimensão já vinha sendo explorada de maneira frutífera pelos modelos de cadeias globais de commodities (CGCs) e cadeias globais de valor (CGVs) (Gereffi e Korzeniewicz, 1994; Gereffi et al., 2005).

3. Assim, desde a década de 1990, autores como Gereffi e Korzeniewicz (1994) e Castells (1999) apon- 
as funções não produtivas - financeiras, de concepção e de mercado - expressa a complexidade dos processos relacionados ao valor, tendo "liberado" as CTNs líderes da incumbência de sua criação, em favor da configuração de mecanismos e arranjos organizacionais e institucionais progressivamente mais sofisticados para a ampliação e captura do valor.

Nesses termos, as relações entre firmas na rede são profundamente assimétricas. Ao longo das últimas décadas, as competências das CTNs em coordenar tais redes têm se ampliado, de modo que arranjos voltados ao compartilhamento de custos, responsabilidades e riscos junto às firmas subordinadas se multiplicaram, promovendo inclusive teorização mais sofisticada acerca dos padrões de governança (Gereffi et al., 2005) específicos a setores. Assim, o modelo das RGPs concebe as relações interfirma a partir da noção de poder corporativo, sendo este definido como capacidade de influência eficaz sobre as decisões corporativas (ação econômica) de outros agentes (econômicos) (Santos, 2011).

Desse modo, CTNs coordenadoras de redes acumulam recursos volumosos e diversificados - da liquidez de capital, passando pelo investimento em PED e chegando à confiança de stakeholders diversificados - e os mobilizam estrategicamente de modo a influenciar a ação econômica desempenhada por outros agentes da rede em benefício próprio, através, por exemplo, da incorporação de padrões técnicos modularizados e do fornecimento de bens intermediários customizados, da constituição de alianças estratégicas etc. Em paralelo, firmas secundárias em RGPs divergem grandemente quanto aos recursos que controlam, podendo ocupar posições diversas quanto à criação, ampliação e captura de valor. Próximas às firmas líderes, fornecedoras globais de primeira camada tendem a exibir trajetórias de upgrading industrial (Humphrey e Schmitz, 2002), enquanto as margens de ação de uma variedade muito grande de firmas permanecem restringidas por padrões de governança estritos - cativos, na terminologia das CGVs (Gereffi et al., 2005) - e limitadas a funções produtivas de baixas tecnologia e valor adicionado.

O modelo das RGPs incorpora ainda uma noção específica de enraizamento apropriada à dimensão interfirma. Nesses termos, o enraizamento de rede opera como uma variável relacional-estrutural, conferindo relevância à cristalização das relações interfirma no que concerne a elementos de arquitetura, forma, duração e equilíbrio (Henderson et al., 2011, p. 453; Santos, 2011, p. 137). Dessa forma, a interação repetida entre os agentes econômicos na rede tende a influenciar seus pa-

tavam a externalização de funções produtivas como elemento chave das estratégias corporativas nos setores têxtil e de telecomunicações. Abreu et al. (2000) demonstraram o mesmo mecanismo na implantação do Consórcio Modular da Volkswagen no Brasil, que se difundiria no setor automobilístico desde então. 
drões de comportamento individual e coletivos futuros, promovendo estabilidade, o que Hess (2004) atribui à confiança como variante particular das relações entre agentes econômicos (Santos, 2011, p. 137).

Não obstante, a dimensão das relações multiagente introduz um componente propriamente inovador, que distingue o modelo das RGPs de outras formas de interpretação, ao conectar "aspectos dos arranjos sociais e espaciais nos quais aquelas firmas estão enraizadas e que influenciam suas estratégias e os valores, prioridades e expectativas dos gestores, trabalhadores e comunidades afins" (Henderson et al., 2011, p. 159).

Essa abordagem coloca em perspectiva a "superagência' das firmas centrais" (Santos, 2011, p. 131) nas relaçôes interfirma (dimensão da "cadeia") não apenas a partir da performance das firmas subordinadas nos processos de valor. Questiona essa interpretação principalmente a partir da fragmentação da agência (Idem) e da incorporação, como variável endógena, de agentes não econômicos, políticos e sociais, tais como "sindicatos, associações patronais e organizações que promovem determinados interesses econômicos (por exemplo, as de pequenas empresas), ONGs preocupadas com os direitos humanos, questões ambientais etc." (Henderson et al., 2011, p. 158).

Os processos relativos ao valor são, nesse sentido, intimamente relacionados às "condições sob as quais a força de trabalho é convertida em trabalho real através do processo de trabalho", remetendo aos "temas do emprego, qualificação, condições de trabalho e tecnologia de produção" (Idem, p. 156), assim como às dinâmicas da reprodução. Mais do que isso, agentes políticos e sociais diversificados são identificados como economicamente relevantes (Weber, 2006), sendo capazes de influir e mesmo definir as condições específicas de criação, ampliação e captura de valor.

$O$ poder coletivo remete às possibilidades de influência que os agentes sociais desfrutam em relação aos agentes econômicos e políticos, condicionando a efetivação de estratégias corporativas. De maneira direta e/ou indireta, tais agentes produzem efeitos sobre as dimensões simbólica e material dessas estratégias, assim como contribuem para configurar as formas de regulação política de suas atividades por meio de práticas de contestação social (Hommel e Godard, 2005). Dentre eles, se destacam os movimentos sociais - classistas e não classistas - por suas capacidades organizacionais e institucionais de sustentar no tempo formas de ação coletiva confrontacional em face de agentes poderosos (Tarrow, 2009), políticos e econômicos.

Adicionalmente, o modelo incorpora variáveis estruturais como relevantes para o entendimento dos STPs contemporâneos. Nesses termos, além do condicionamento exercido pelas relações interfirma, os autores destacam o papel das "relações sociais lato sensu sobre a atividade econômica e seus agentes" (Santos, 2011, p. 136). Teoricamente, a noção ampla de enraizamento (Granovetter, 1985) concebe a ação 
econômica como constituída e inseparável de redes de relações sociais ininterruptas, que provocam efeitos estruturantes sobre o comportamento de agentes coletivos e individuais.

Dessa forma, autores como Hess (2004) destacaram a importância das instituições sociais "de origem" na constituição e na estruturação do comportamento dos agentes - econômicos e não econômicos. Nesses termos, o enraizamento social abrange os condicionamentos institucionais da ação social de tipo econômico, suportando e constrangendo as opções disponíveis às CTNs no plano de suas estratégias corporativas, em particular no que respeita às estruturas organizacionais e regulatórias nacionais ${ }^{4}$.

$\mathrm{O}$ complemento à dimensão de origem do enraizamento no condicionamento da ação econômica é o "plano de destino". Considerando a desintegração espacial funcional da ação econômica das CTNs, os modos específicos de efetivação de suas estratégias corporativas em rede são concebidos como influenciados de maneira decisiva por dinâmicas socioeconômicas já existentes (Henderson et al., 2011, p. 160), promovendo uma espécie de "ancoragem territorial ou de lugar" (Santos, 2011, p. 137), que vem sendo continuamente demonstrada a partir de investigações empíricas (Ramalho, 2005; Ramalho et al., 2013).

\section{RGPS como redes de trabalho incorporado}

Não obstante as possibilidades abertas por esta abordagem, alguns autores identificam suas lacunas e limitações específicas quanto à incorporação do trabalho e dos trabalhadores. De modo geral, segundo Coe e Hess (2013), as análises empíricas das RGPs têm se limitado a apontar os desafios colocados aos trabalhadores e sindicatos pelo aprofundamento da fragmentação geográfica e integração funcional da atividade econômica. Em particular, a investigação amparada pelo modelo vinha se desenvolvendo, grosso modo, de maneira "independente da literatura sobre os impactos dos sistemas globais de produção sobre os trabalhadores e suas possíveis respostas" (Idem, p. 5). Nesses termos, para os autores, a literatura contemporânea sobre RGPs “tem se mantido, em grande medida, silenciosa sobre a questão da agência dos trabalhadores" (Idem).

Especificamente, autoras como Phillips (2011, p. 381) destacam que, "apesar da riqueza da produção acadêmica sobre informalidade e economias informais em todas as ciências sociais, [...] a atenção teórica e empírica à informalidade permanece bastante limitada na investigação contemporânea sobre RGPs”. Essa literatura é,

\footnotetext{
4. A categoria de enraizamento social remete a uma perspectiva centrada na diversidade institucional, com destaque para o debate das variedades de capitalismo (VDC) (Hall e Soskice, 2001).
} 
assim, acusada de compartilhar uma concepção de informalidade como "condição 'residual'” (Idem, p. 385). Em sentido contrário, a

[...] informalidade e a formalidade não existem como esferas da vida econômica e social distintas (e separadas), mas são interligadas de maneiras complexas. [...] Esta mescla estrutural é tanto um resultado do funcionamento de RGPs quanto um processo-chave em sua constituição e evolução (Idem, p. 382).

Entendida como elemento constitutivo de RGPs, a informalidade compõe processos de construção e reprodução de uma força de trabalho fundamentalmente estratificada (Iem, pp. 385-386). Essa conformação responde tanto às demandas de flexibilidade organizacional da firma quanto expressa uma "estratégia política para o disciplinamento da força de trabalho" (Idem, p. 386). Dessa forma, "o processo dinâmico de informalização é central para essa estratégia, dirigido conscientemente pelas firmas e, em um sentido estrutural, instaurado pelas características da operação de RGPs" (Idem).

Um desdobramento importante dessa discussão remete ao tema da agência. Embora tenha havido certa exortação para o maior engajamento de análises sobre STPs com os contextos socioeconômicos locais e as relações de trabalho, parece ser recente a emergência de posições teórico-metodológicas nesse campo que favoreçam uma interpretação das "pessoas da classe trabalhadora como seres sociais sensíveis que, tanto intencionalmente quanto sem querer, produzem geografias econômicas através de suas ações” (Herod, 2001, p. 15 apud Carswell e De Neve, 2013, p. 63).

Mesmo os trabalhos que defendem concepções similares tendem a se apoiar em um "conceito bastante estreito de agência dos trabalhadores" (Carswell e De Neve, 2013 , p. 63), vinculado à ação coletiva institucionalizada sob forma sindical, quando, em grande medida, o esforço central pretendido pelos autores busca "reconectar a acumulação e a reprodução do capitalismo às próprias práticas de sobrevivência e reprodução social dos trabalhadores" (Idem).

Mais importante, a agência dos trabalhadores, quando considerada, tem sido interpretada "primariamente em termos de resistência" (Idem), em detrimento da diversidade de maneiras pelas quais agentes sociais vivem e trabalham e acabam por influenciar as formas específicas de manifestação dos nós de RGPs. Essa debilidade específica se combina a uma "quase completa ausência de atenção a atos individuais e a práticas cotidianas e informais através das quais os trabalhadores constroem suas vidas de trabalho" (Idem, p. 64).

Desse modo, as autoras defendem uma tipologia da agência dos trabalhadores em termos de "resiliência, retrabalho e resistência" (Katz, 2004 apud Carswell e De 
Neve, 2013, p. 63). Assim, as formas concretas pelas quais trabalhadores se vinculam a RGPs podem ser vistas em sua multiplicidade, partindo das ações orientadas à adaptação e recuperação de situações adversas, passando por atos de redefinição de circunstâncias de opressão e/ou desigualdade e chegando mesmo às ações voltadas à subversão dessas condições de exploração (Carswell e De Neve, 2013, p. 63). Nessa concepção, as condições empíricas de manifestação da dialética resistência-consentimento (Burawoy, 1979; Beynon, 1995) adquirem importância central, em detrimento das formas "modelares" de agência.

Barrientos et al. (2011, p. 303) observam, entretanto, que "a literatura sobre RGPs tem se concentrado cada vez mais nas implicações em termos de upgrading e downgrading para os trabalhadores incorporados nessas redes globais"' . Essa corrente destaca, assim, as formas de incorporação de grupos específicos de trabalhadores, dando ênfase ao papel da subcontratação em RGPs em sua conformação. Assim, coloca em questão a dialética entre as pressões em rede para explorar a diversidade das práticas de rebaixamento dos custos com a força de trabalho e contrapressões sobre as firmas fornecedoras para crescentemente atingir padrões de qualidade e acessar trabalhadores mais qualificados (Idem, p. 305).

Os fundamentos desse corpo teórico são a concepção de um "déficit global de governança" e a emergência empírica de arranjos de "governança privada" ou multistakeholder e formas transnacionais de organização dos trabalhadores (Idem). Em particular, esforços voltados à conformação de padrões trabalhistas mínimos quanto à liberdade de associação e à negociação coletiva - como as federações sindicais globais ${ }^{6}$ e os acordos-marco internacionais ${ }^{7}$ - tendem a inscrever o trabalho decente nas RGPs. Para os autores, são exatamente essas “instituições de governança híbridas e complementares, tanto públicas quanto privadas, operando em múltiplos níveis - global, nacional e local”, que têm o potencial de “'reenraizar' os mercados globais" (Idem, p. 313).

Selwyn (2013, pp. 87-88) reconhece que a noção de upgrading social e a renovada ênfase por ela proporcionada às condições de trabalho constituem uma tentativa importante de suprir a deficiência em questão. Entretanto, o autor assume uma posição crítica ao conceito, derivado da agenda sobre trabalho decente impulsionada

5. Os autores partem da crítica aos diferentes modelos de STPS quanto à sobrevalorização dos processos de upgrading econômico - por meio dos quais firmas e governos redefinem sua posição em cadeias de valor no que concerne ao valor adicionado, à tecnologia e às capacidades produtivas - e à subteorização das condições e relações de trabalho, compreendidas pela noção de upgrading social (Barrientos et al., 2011, p. 301).

6. Global Union Federations (GUF), no original em inglês.

7. International Framework Agreements (IFA), no original em inglês. 
pela Organização Internacional do Trabalho (OIT). Para ele, essa agenda sintetiza uma "concepção de 'cima para baixo' de upgrading social", demonstrando certa "incapacidade de compreender a natureza da exploração capitalista e do trabalho indecente" (Idem, p. 76).

Os arranjos institucionais centrados no trabalho decente devem, portanto, ser entendidos como "resultados de e/ou respostas a lutas potenciais entre capital e trabalho" (Idem, p. 83). Para o autor, uma releitura da explicação marxiana do processo de trabalho permitiria superar essa debilidade, explicitando as causas do trabalho indecente e das formas de resistência dos trabalhadores, e assim desenvolver uma "concepção 'de baixo para cima”" (Idem, p. 76) de upgrading social. O autor apoia, então, uma interpretação da agência centrada na "indeterminação da força de trabalho" (Idem, p. 78), reforçando a ideia de que "a habilidade dos trabalhadores em transformar seu poder estrutural em associativo de modo a extrair concessões do capital constitui um determinante central da relação entre upgrading econômico e social" (Idem, pp. 83-84) em RGPs.

Quanto às modalidades "indecentes", começa a ocupar lugar relevante nas análises de RGPs mais recentes (Phillips e Sakamoto, 2012; McGrath, 2013) o tema das condições e relações de trabalho degradantes e restritivas à liberdade que constituem o trabalho escravo contemporâneo.

Em particular, o trabalho de McGrath (2013) defende que "as dinâmicas das redes de produção são fundamentais para a reprodução do trabalho escravo" (Idem, p. 32). Analisando o nó brasileiro da RGP do etanol, a autora demonstra como a ação econômica coordenada por compradores (buyer-driven) e pelo Estado brasileiro (state-driven), por meio de pressões encadeadas sobre as firmas subordinadas, conforma as relações sociais ao longo de toda a rede, sendo funcionais à sua reprodução.

Dinâmicas estruturais são consideradas, ainda, fundamentais para "facilitar a imposição de restrições sobre a mobilidade dos trabalhadores, de condições degradantes e da intensificação do trabalho" (Idem, p. 32), sendo decisivos os processos de racialização. Levando em conta que identidades sociais incorporadas, como etnia, gênero etc., condicionam os julgamentos acerca do valor, grupos específicos de trabalhadores enfrentam situações desiguais para negociar suas condições específicas, de modo que "a reprodução do trabalho escravo [no Brasil] se sustenta em um processo de desvalorização do trabalho que opera através de ideologias de raça (e gênero)" (Idem, p. 38). Dessa forma, a autora apresenta uma importante contribuição para o entendimento do racismo como relação social de produção e dos mecanismos de desvalorização do trabalho a ele associados em RGPs.

Phillips e Sakamoto (2012) direcionam sua atenção para a relação entre as formas específicas e desiguais da integração em RGPs e outra dinâmica estrutural, a saber, a 
da pobreza crônica. Dessa forma, os autores colocam em primeiro plano o conceito de "incorporação adversa" (Idem, p. 288) em RGPs de modo a identificar os padrões de inclusão capazes de construir e sustentar a pobreza, dentre os quais o trabalho escravo se destaca como manifestação extrema.

Os autores defendem que as formas prevalentes de restrição à liberdade no nó brasileiro da RGP pecuária são antes contratuais e de curto prazo do que tradicionais (Idem, p. 292), sendo que os dados mobilizados demonstram que "não são os mais pobres entre os mais pobres os mais vulneráveis a essas formas extremas de exploração do trabalho" (Idem, p. 303).

A incorporação adversa é, portanto, entendida como um "fenômeno 'relacional" (Idem, p. 296), isto é, dependente dos “termos nos quais diferentes grupos sociais são incorporados na atividade econômica global” (Idem, p. 297). Esses termos são continuamente reconfigurados pela vulnerabilidade desigual desses grupos, afetando os resultados de sua inclusão via trabalho a partir dos modos como os indivíduos que os integram agem orientados por resultados de curto prazo e necessidades práticas, comprometendo formas de satisfação de necessidades e de garantia de direitos no longo prazo.

Coe e Hess (2013, p. 4) identificam, por sua vez, uma preocupação exacerbada dos estudos empíricos de RGPs “com a análise da produção de bens, à custa de considerações sobre o consumo final” e sobre o descarte. Considerando a importância dos processos de “'fatiamento' de cadeias de valor e de criação de novos circuitos de capital através de seu 'alongamento"' (Idem, p. 5) - do comércio popular à coleta de material reciclável -, esse descuido explica a baixa acuidade do modelo para incorporar o "trabalho formal e o informal e as [diversas] formas de ganhar a vida" (Idem, p. 4) periféricas às RGPs. Entretanto, esses nós parecem ser decisivos no que diz respeito à governança de RGPs, condicionando os processos relacionados ao valor ${ }^{8}$.

Não obstante, McGrath-Champ et al. (2015) introduzem uma perspectiva inovadora à discussão, relacionando os "pontos cegos" do trabalho e do descarte e reconstituindo-os como eixos analíticos das RGPs. Dessa forma, os autores deslocam a ênfase dos nós produtivos da rede para aqueles nos quais bens descartados são desmontados para processamento visando reuso e reciclagem, conformando, nesse sentido, "redes globais de destruição" (RGDs) (Idem, p. 626).

Consequentemente, entendido o valor como trabalho cristalizado que não se encerra na destruição do produto, as RGDs emergem como “indelevelmente imbrica-

8. Através, por exemplo, de estratégias de responsabilização de CTNs líderes acerca das condições de trabalho ao longo das cadeias de valor e de "respostas" centradas em códigos de conduta, responsabilidade social corporativa (RSC), mecanismos de governança privada e autorregulação, além de regulação pública estatal e interestatal (Coe e Hess, 2013, p. 5). 
das, e um Outro indispensável às RGPs” (Herod et al., 2014, p. 427 apud McGrath-Champ et al., 2015, p. 631), vinculando "aqueles que trabalham no mercado de trabalho 'formal' produzindo novas mercadorias" ao "trabalho informal" daqueles trabalhadores que labutam em RGDs para recuperar partes úteis de mercadorias descartadas (McGrath-Champ et al., 2015, p. 632).

Dessa forma, um enorme contingente de seres humanos considerados "estruturalmente redundantes para os processos globais de acumulação", isto é, "trabalhadores descartados" (Idem, p. 633), são entendidos como parte decisiva da construção da oferta dos fatores de produção para inúmeras redes de produção. Suas conexões tornam, assim, muito "mais porosas" (Idem, p. 635) as distinções entre os setores formal e informal.

Por fim, Cumbers et al. (2008) reintroduzem o trabalho no debate sobre RGPs a partir de estratégias trabalhistas globais em rede (Idem, p. 371). Dessa forma, os autores pretendem redefinir o espaço do trabalho no debate dos sistemas transnacionais de produção, em favor de uma perspectiva que considera o controle do processo de trabalho como eixo de luta à medida que "as RGPs são, em última instância, redes de trabalho incorporado” (Idem, p. 372).

\section{Sindicatos como agentes constitutivos de RGPS}

Considerando a categoria social trabalho como um espaço de "luta de classe contínua”, torna-se necessário conceber o sindicato como forma de organização de interesses "que tanto ajuda a reforçar a acumulação de capital quanto oferece espaços de resistência" (Cumbers et al., 2008, pp. 373-374). Essa perspectiva recoloca a dimensão propriamente política das estratégias sindicais, compreendidas sob o panorama contraditório das relações capital-trabalho, que tanto podem empoderar quanto marginalizar agentes sindicais por meio de RGPs, "conduzindo a consideráveis conflito e tensões internas no âmbito de redes globais sindicais" (Idem, p. 375).

As competências de "coordenação à distância" detidas pelas CTNs vêm permitindo, assim, explorar e articular estrategicamente uma grande diversidade das condições de vida e relações de trabalho no que diz respeito ao custo, qualificação e organização e à propensão ao conflito em escala global. Não obstante, as capacidades organizacionais e institucionais de coordenação distanciada da ação social de tipo econômico têm sido emuladas e reconstruídas a partir da experiência acumulada pelas organizações de representação sindicais.

Para Cumbers et al. (Idem, p. 371), "os antagonismos, entre cooperar e resistir à acumulação de capital, vão variar bastante entre diferentes grupos de trabalhadores dentro das redes globais de produção". Esses autores defendem que é com o desenvol- 
vimento de uma perspectiva crítica do trabalho como agência que se deve interpretar o posicionamento dos sindicatos na economia global (ver também Munck, 1999).

Os autores (Idem, pp. 373-374) consideram que os sindicatos devem ser vistos "como organizações que representam elementos particulares de uma classe trabalhadora que tem geografias distintas". E, por consequência, identificam uma diversidade de posições, que vão desde organizações sindicais com a aspiração de unificar a classe operária contra o capital global ao nível ideológico até sindicatos mais conservadores que se comprometem com princípios da justiça social global. Para eles, as ações sindicais são cada vez mais complexas e divididas, refletindo as diversas realidades materiais dos trabalhadores que representam.

Para Gumbrell-McCormick e Hyman (2013), os sindicatos frequentemente ficam desorientados e sem clareza sobre seu papel no atual contexto, diante do poder corporativo das CTNs, assim como da incapacidade dos governos de resistir às pressões por integração econômica. No entanto, reconhecem que os sindicatos continuam a ser atores socioeconômicos relevantes e que os tempos difíceis "podem estimular um novo pensamento, trazendo novas oportunidades" (Idem, p. 1).

Parte das análises sobre os efeitos da globalização econômica tem enfatizado uma estratégia de enfraquecimento e destruição do movimento trabalhista e sindical. Mais recentemente, contudo, um grupo consistente de sociólogos e historiadores do trabalho (Burawoy, 2010; Evans, 2010; Munck, 2010; 2013; Ramalho, 2014; Webster, 2010) iniciou um processo de revisão dessa interpretação. Um dos postulantes dessa perspectiva, Evans (2010, p. 353), critica posições que enfatizam a destruição do movimento trabalhista pelo neoliberalismo e pela globalização. Para ele, a globalização econômica, tanto pelo encolhimento do espaço social e geográfico como pelas estruturas específicas do capitalismo neoliberal contemporâneo, estimula e facilita a mobilização da solidariedade do trabalho em nível transnacional, assim como a construção de organizações e redes do movimento trabalhista.

O autor alerta, entretanto, que "a eficácia da resposta do trabalho não se encontra na invenção de uma única forma organizacional, mas na interconexão de diferentes formas" (Idem, p. 354), diante dos desafios postos pelo contexto político e pelos diferentes tipos de capital. Ademais, o reconhecimento dessas oportunidades globais complementa a contínua centralidade dos conflitos políticos em níveis nacional e local nos quais se constituem os mecanismos de contestação. Dessa forma, sua contribuição direciona a atenção à arena global como uma fonte potencial de vantagem estratégica, em vez de pensá-la como a principal explicação para o declínio.

Evans (Idem, pp. 353-354) identifica assim a "diversidade de ações estrategicamente concatenadas" como condição necessária de reação às ameaças da transformação global da estrutura de emprego e do discurso da ausência do poder dos sindicatos 
diante da ofensiva do capital global. $\mathrm{O}$ autor ressalta que "o acúmulo gradual de experiência e construção institucional e a emergência contínua de novos casos" (Idem, p. 354) demonstra um processo de mobilização transnacional ascendente, e, ainda que suas expressões não tenham muito sucesso, elas podem estar na base de processos de fortalecimento institucional com potencial futuro significativo.

Na avaliação de Munck (2010, p. 220), a partir dos anos 2000, o movimento sindical internacional passou a investir na construção de "estratégias sindicais inovadoras", como forma de enfrentar os impactos negativos da globalização e suas expressões sob a forma de divisões nacionais, setoriais e ideológicas e do "velho problema de rotinização e burocracia do movimento trabalhista" (Idem, p. 227). Para Webster (2010, pp. 384-385), essa perspectiva indica que "o global está frequentemente no local e de que não é mais possível ver a organização sindical como uma atividade puramente local".

Para Munck (2013, p. 237), "mais recentemente, a teoria social crítica adicionou a mais do que necessária dimensão espacial na análise da economia política do trabalho", a partir da incorporação da noção de "escala". "O movimento trabalhista opera claramente nos níveis local, nacional, subregional, regional, subglobal e global através de diferentes formas organizacionais desde as confederações sindicais internacionais até os sindicatos locais" (Idem, p. 239). Para esse autor, as escalas de ação política do movimento sindical devem ser vistas de modo hierarquizado, e as organizações dos trabalhadores precisam "fazer conexões" através das escalas.

Dessa forma, a busca de formas sindicais inovadoras com vistas a uma articulação e uma atuação internacional tem fortalecido nas duas últimas décadas "uma textura em processo de institucionalização de regulação transnacional do trabalho" (Pries e Seeliger, 2013, p. 26). Para esses autores, "esse processo tem que ser entendido como uma forma de restringir a lógica dos mercados e dos interesses nacionais e corporativos e uma forma de institucionalizar a lógica dos padrões mínimos, dos atores coletivos e da sociedade civil" (Idem, p. 27). O argumento é o de que a pressão de sindicatos e outras organizações da sociedade civil reforça a criação de novas iniciativas de regulação dos padrões de trabalho e o desenvolvimento de novas dinâmicas de regulação que ultrapassam as fronteiras nacionais. Citam como exemplo, entre outros, os comitês mundiais de trabalhadores de empresas internacionais, as federações globais sindicais e os acordos-marco internacionais.

Pries e Seeliger (Idem, pp. 29-30) valorizam, nesse contexto, a presença em nível global de um conjunto mínimo de padrões de amplo alcance, tais como as "normas essenciais da OIT" (ILO-core norms), por constituírem "uma base ética favorável à formulação de requisitos básicos para as condições de trabalho e emprego em todo o mundo". E reconhecem que, diante da diversidade das condições de seu cumpri- 
mento, sua constituição é uma oportunidade para criar referenciais substantivos para as reivindicações por condições decentes de trabalho e definir novos marcos de legitimidade que afetam os agentes econômicos e políticos.

$\mathrm{Na}$ mesma linha argumentativa, Walby (2011, p. 141 apud Pries e Seeliger, 2013, p. 39) reconhece que, embora os direitos humanos possam ser vistos como “meramente uma lista de objetivos”, eles se enraízam na estrutura de agentes políticos interestatais legítimos, como é o caso da OIT, e podem ser usados como ferramentas políticas ${ }^{9}$ para melhorar as condições de trabalho, emprego e participação social.

Pries e Seeliger (2013, p. 31) insistem em reconhecer que os diferentes mecanismos de regulação transnacional do trabalho podem se institucionalizar e construir partes dos complexos campos organizacionais transnacionais. A "questão crucial é até onde diferentes mecanismos de regulação do trabalho coletivo e transnacional são percebidos e trabalham como padrões institucionalizados que forjam o comportamento de todos os atores no campo organizacional". Os autores atribuem importância aos acordos-marco como "ferramentas para reforçar o reconhecimento e a implementação dos padrões trabalhistas mínimos e como um contrato entre sindicatos e corporações transnacionais". Tais dispositivos têm quatro objetivos: (1) assegurar a concordância com os padrões mínimos de trabalho da OIT; (2) o reconhecimento da federação sindical mundial como parceiro de negociação; (3) a institucionalização de mecanismos coletivos globais de resolução de conflitos; e (4) a organização da solidariedade transnacional.

Nesse ponto, a agência é determinante. Para Pries e Seeliger (Idem, pp. 31-32), por exemplo, "os padrões trabalhistas mínimos estabelecidos pela OIT nas oito principais convenções assinadas pela maioria dos países em todo mundo não terão quase efeito sobre o trabalho e as condições de emprego se ao nível nacional não houver atores coletivos fortes (sejam agências do estado, movimentos sociais, sindicatos, organizações de consumidores) para promovê-los”.

Nesses termos, Cumbers et al. (2008, p. 384) identificam uma tendência de crescimento do número de sindicatos que estabelecem suas próprias redes globais. Para esses autores, os sindicatos, nesse processo, percorrem um caminho delicado entre a cooperação com as CTNs e a criação de redes ligadas ao trabalho mais independentes.

Às vezes, o melhor meio de desenvolver efetivamente uma rede do trabalho transnacional é através dos próprios espaços das empresas multinacionais, mas os sindicalistas têm que ter

9. Essa posição se defronta, no entanto, com leituras mais críticas sobre a efetividade de acordos globais tripartite. Para Munck (2013), seu apelo reformista coloca em dúvida sua capacidade como projeto de transformação do movimento trabalhista. 
sensibilidade para com a complexidade das posições ao lidar com as relações dialéticas entre capital e trabalho, em particular quando tentam traduzir as práticas nacionais para a escala transnacional (Idem, p. 385).

A contribuição de Hyman (2001) acerca do movimento sindical europeu fornece elementos para uma análise sociológica mais acurada da realidade vivida por sindicatos impactados pela globalização, obrigados a rever suas estratégias políticas e operacionais, principalmente no sentido da manutenção do emprego e da sua sobrevivência como instituição. Para ele (Idem, pp. 3-4), mercado, classe e sociedade constituiriam a "geometria do sindicalismo", conectados em um balanço triangular instável. Nesses termos, os focos no mercado, na sociedade ou na classe não existiriam sob forma pura, de maneira que "os sindicatos hoje tendem a se inclinar para uma mistura desses três tipos ideais" ${ }^{10}$. Assim,

Como associações de empregados, [os sindicatos] têm uma preocupação central de regular a relação trabalhista-salarial: o trabalho que desempenham e o pagamento que recebem. Sindicatos não podem ignorar o mercado. Mas como organizações de trabalhadores, os sindicatos incorporam, além disso, uma concepção de interesses coletivos e identidade coletiva que divide os trabalhadores dos empregadores. Se endossam ou não uma ideologia da divisão de classe ou da oposição de classe, os sindicatos não podem escapar ao papel de agências de classe. No entanto, os sindicatos também existem e funcionam em uma base social que eles podem aspirar mudar, mas que constrangem suas escolhas atuais. Sobrevivência necessita coexistência com outras instituições e outras constelações de interesse (mesmo para aqueles sindicatos que proclamam um antagonismo imutável). Os sindicatos são parte da sociedade. (Idem, pp. 3-4).

Na avaliação de Fairbrother e Webster (2008, p. 310), "os sindicatos são um tipo de movimento social que contém dimensões progressistas e acomodatícias”, e a questão que se coloca para os analistas é identificar "como e em que circunstâncias os sindicatos podem desafiar e questionar a relação capital/trabalho" (Idem, 2008, p. 310). Além disso, de acordo com Hyman e Gumbrell-McCormick (2010, p. 315), os "sindicatos não são apenas atores econômicos: eles são necessariamente protagonistas na arena política”. Desse modo, sindicatos detêm e exercem formas de poder que vão do âmbito da regulação cotidiana das condições de compra e venda da força de

10. Essa interpretação reforça argumentos que consideram posições políticas e estratégias sindicais como fruto de avaliações permeadas pelos contextos locais, regionais e nacionais, de tradições políticas incorporadas historicamente às práticas sindicais, de conjunturas econômicas globais e nacionais e seus desdobramentos sobre o mercado de trabalho e o aumento do desemprego (Fairbrother e Webster, 2008). 
trabalho no mercado de trabalho à influência indireta que exibem sobre as formas através das quais "o Estado molda as regras do jogo no mercado de trabalho, incluindo o seu direito de existir, para negociar coletivamente e para mobilizar para a ação coletiva" (Hyman, 2001, pp. 13-15).

Segundo Gumbrell-McCormick e Hyman (2015, pp. 12-13), sendo os sindicatos organizações primordialmente de base nacional, assim como as identidades coletivas e as concepções subjetivas de interesse comum que os sustentam, para serem efetivas, suas estratégias tiveram de ser desenvolvidas com base "na reciprocidade apesar das diferenças" nessa escala. Os desafios postos hoje a sua ação não apenas mudaram de escala, mas as atravessam de formas diversas. Esse elemento impõe desafios desiguais e combinados ao desenvolvimento de novas solidariedades no mundo do trabalho.

Assim, para esses autores, formas múltiplas de solidariedade demandam aos sindicatos desafiar consistentemente as pressões centrífugas, corporativas e institucionais - os sindicatos têm que criar uma narrativa e um discurso alternativos. Nesse processo, o diálogo entre sindicalistas de diferentes nacionalidades é obviamente central, sendo necessariamente "multiescalar" (Gumbrell-McCormick e Hyman, 2015, p. 13). "Solidariedade é multifacetada e envolve elementos objetivos e subjetivos. Os interesses não são dados, mas socialmente construídos, em geral em situação desvantajosa” (Idem, p. 13). Para os autores, a tarefa básica dos sindicatos seria estimular a percepção dos trabalhadores com vistas a "um entendimento solidário de suas próprias situações em relação à posição dos outros e prover a base para relações de cooperação e ação comum" (Idem, p. 13).

\section{Conclusão}

A abordagem das RGPs, em resumo, fornece um instrumental teórico sofisticado para analisar os STPS contemporâneos. Em particular, o referido enfoque se destaca por duas dimensões. Em primeiro lugar, o modelo teórico-metodológico das RGPs valoriza as variadas possibilidades de influência que os agentes sociais desfrutam em relação aos agentes econômicos e políticos, condicionando a efetivação de estratégias corporativas centradas no valor, assim como perspectivas e trajetórias de desenvolvimento econômico. Entre esses agentes queremos enfatizar os movimentos sociais - classistas e não classistas -, tendo em conta suas capacidades organizacionais e institucionais de sustentar no tempo formas de ação coletiva confrontacional.

Dessa forma, a abordagem é promissora no que concerne a uma possível reconfiguração da forma como os estudos sobre o mundo do trabalho têm se desenvolvido - em particular, no âmbito da sociologia -, mantendo-se, em grande medida, afastados dos achados teóricos e empíricos acerca dos formatos organizacionais das firmas e 
da evolução para redes globais funcionais e desintegradas, coordenadas por CTNs. Nesses termos, uma compreensão relacional dos destinos de firmas e trabalhadores é não apenas necessária, como parece decisiva para a compreensão dos padrões de interação entre capital e trabalho no capitalismo contemporâneo.

Por sua vez, a abordagem também é sensível para as escalas diferenciadas nas quais a ação social - de tipos econômico e não econômico - se desenrola. Em sentido prático, diferentes grupos de trabalhadores vêm se movendo entre as escalas da ação política de sindicatos e outros movimentos sociais para contestar cotidiana, mas também estruturalmente, a efetivação de estratégias corporativas. Não obstante, em planos teórico e metodológico, as ferramentas mobilizadas na investigação dos diversos mundos do trabalho têm permanecido vinculadas a matrizes tipicamente locais e nacionais, caminhando de modo tímido por outras trilhas. Dessa forma, parece igualmente importante reconstruir as relações entre capital e trabalho em sentido multi e transescalar, com especial atenção aos aspectos inovadores da organização do poder coletivo dos trabalhadores.

Não obstante as possibilidades abertas pelo modelo, esse balanço de literatura também mostrou debilidades no que diz respeito ao "reconhecimento crescente das muitas formas diferentes de trabalho que estão inscritas em RGPs" (Coe e Hess, 2013 , p. 5) e que o modelo não vinha sendo operacionalizado no sentido de uma incorporação plena e dialética dos trabalhadores como agentes chave na conformação da globalização econômica.

Dessa forma, o conjunto de contribuições que visa preencher essa lacuna demonstra enorme potencial para reconstituir uma compreensão relacional da conformação das estratégias corporativas em rede e de uma classe trabalhadora profundamente estratificada, implicando condições mais complexas de consentimento e resistência. Nesses termos, parece central o aprofundamento das investigações acerca das formas de integração assimétrica e funcional das frações da classe trabalhadora, tendo em conta segmentações étnica, de gênero, regional etc. e os processos estruturais de diferenciação que os sustentam - generificação, racialização, regionalização etc.

Mais importante, essas contribuições destacam a natureza fragmentada e contraditória, individual e coletiva, da agência dos trabalhadores. De fato, os trabalhadores e suas organizações de representação configuram uma matriz constitutiva da globalização econômica. Não obstante, sua conformação empírica não se reduz, de modo algum, a modelos de ação predeterminados, grandemente apoiados na experiência histórica de categorias organizadas de trabalhadores oriundas de segmentos $\mathrm{da}$ indústria e com forte componente idealizado.

De fato, a "fragmentação" da agência proposta pelo modelo das RGPs precisa ser radicalizada e incorporada pelos estudos do trabalho, de modo a reconstituir as 
condições empíricas a partir das quais os trabalhadores se vinculam a cadeias de valor extensão, que partem da extração, passam pela produção, distribuição e consumo, mas não se esgotam no descarte, reconstituindo incessantemente tanto os ciclos de acumulação de capital quanto as condições de sua ruptura periódica.

Finalmente, longe de haver perdido centralidade, as formas organizacionais vinculadas à representação sindical vêm sendo reconfiguradas incessantemente, emulando práticas corporativas em rede, mas também se desenvolvendo a partir de repertórios históricos e inovações institucionais. Em grande medida, o debate internacional sobre o escalonamento da ação coletiva sindical vem demonstrando o renovado potencial político dos sindicatos e sua contínua capacidade de pautar a agenda pública em torno da melhoria das condições e relações de trabalho.

Retomando a ideia de que o mundo do trabalho éper se um espaço permanente da luta de classes, as opções abertas à reconfiguração dos rumos da globalização econômica pela agência dos trabalhadores continuam a passar pela forma sindicato e sua capacidade de se reinventar.

\section{Referências Bibliográficas}

Abreu, Alice et al. (2000), “'The dream factory': VW's modular production system in Resende, Brazil". Work, Employment \& Society, 14 (2):265-282.

BARRIENTOS, Stephanie et al. (2011), "Decent work in global production networks: framing the policy debate". International Labour Review, 150 (3-4): 297-317.

BEYNON, Huw. (1995), Trabalhando para Ford: trabalhadores e sindicalistas na industria automobilistica. Rio de Janeiro, Paz e Terra.

Burawoy, Michael. (1979), Manufacturing consent: changes in the labor process under monopoly capitalism. Chicago, University of Chicago Press.

. (2010), "From Polanyi to Pollyanna: the false optimism of global labor studies". Global Labour Journal, 1 (2): 301-313.

CARswell, Grace \& De Neve, Geert. (2013), "Labouring for global markets: conceptualising labour agency in global production networks". Geoforum, 44: 62-70.

Castells, Manuel. (1999), A sociedade em rede: a era da informação: economia, sociedade e cultura. São Paulo, Paz e Terra.

Coe, Neil M. \& Hess, Martin. (2013), “Global production networks, labour and development”. Geoforum, 44: 4-9.

Cumbers, Andy et al. (2008), "Labour agency and union positionalities in global production networks". Journal of Economic Geography, 8 (3): 369-387.

Dicken, Peter. (2010), Mudança global: mapeando as novas fronteiras da economia mundial. Porto Alegre, Bookman. 
Evans, Peter. (2010), "Is it labor's turn to globalize? Twenty-first century opportunities and strategic responses”. Global Labour Journal, 1 (3): 352-379.

Fairbrother, Peter \& Webster, Edward. (2008), “Social movement unionism: questions and possibilities". Employee Responsibilities and Rights Journal, 20 (4): 309-313.

GerefFi, Gary et al. (2005), “The governance of global value chains”. Review of International Political Economy, 12 (1): 78-104.

Gereffi, Gary \& Korzeniewicz, Miguel (orgs.). (1994), Commodity chains and global capitalism. Westport/Londres, Praeger.

Granovetter, Mark. (1985), "Economic action and social structure: the problem of embeddedness". American Journal of Sociology, 91 (3): 481-510.

Gumbrell-McCormick, Rebecca \& Hyman, Richard. (2013), “Os sindicatos na Europa Ocidental: tempos difíceis, escolhas difíceis”. Global Labour Column, 148: 1-3.

. (2015), "International trade union solidarity and the impact of the crisis". European Policy Analysis, 1: 1-16.

Hall, Peter A. \& Soskice (orgs.). (2001), Varieties of capitalism: the institutional foundations of comparative advantage. Oxford, Oxford University Press.

Henderson, Jeffrey et al. (2011), "Redes de produção globais e a análise do desenvolvimento econômico”. Revista Pós Ciências Sociais, 8 (15): 143-170.

Hess, Martin. (2004), “'Spatial' relationships? Towards a reconceptualization of embeddedness”. Progress in Human Geography, 28 (2): 165-186.

Hommel, Thierry \& Godard, Olivier. (2005), “Contestação social e estratégias de desenvolvimento industrial: aplicação do modelo da gestão contestável à produção industrial de ogm”. In: Varella, Marcelo Dias \& Barros-Platiau, Ana Flávia (orgs.). Organismos geneticamente modificados. Belo Horizonte, Del Rey, pp. 251-284.

Humphrey, John \& Schmitz, Hubert. (2002), "How does insertion in global value chains affect upgrading in industrial clusters?”. Regional Studies, 36 (9): 1017-1027.

Hyman, Richard. (2001), Understanding european trade unionism: between market, class and society. Londres, Sage.

Hyman, Richard \& Gumbrell-McCormick, Rebecca. (2010), “Trade unions, politics and parties: is a new configuration possible?". Transfer: European Review of Labour and Research, 16 (3): 315-331.

McGrath, Siobhán. (2013), "Fuelling global production networks with slave labour? Migrant sugar cane workers in the Brazilian ethanol GPN”. Geoforum, 44: 32-43.

McGrath-Champ, Susan et al. (2015), "Global destruction networks, the labour process and employment relations". Journal of Industrial Relations, 57 (4): 624-640.

Mello E Silva, Leonardo et al. (2015), Redes sindicais em empresas transnacionais: enfrentando a globalização do ponto de vista dos trabalhadores. São Paulo, Friedrich-Ebert-Stiftung Brasil. MuncK, Ronaldo. (1999), "Labour dilemmas and labour futures”. In: $\&$ WATERMAN, 
Peter. Labour Worldwide in the era of globalization: alternative union models in the new world order. Basingstoke, Macmillan, pp. 3-23.

. (2010), "Globalization and the labour movement: challenges and responses". Global Labour Journal, 1 (2): 218-232.

. (2013), "Global crisis: global opportunity? Trade unions, migration and social transformation". Global Labour Journal, 4 (3): 236-251.

Phillips, Nicola. (2011), "Informality, global production networks and the dynamics of 'adverse incorporation”. Global Networks, 11 (3): 380-397.

Phillips, Nicola \& SAкамото, Leonardo. (2012), “Global production networks, chronic poverty and 'slave labour' in Brazil". Studies in Comparative International Development, 47 (3): 287-315.

Pries, Ludger \& SeELIGer, Martin. (2013), "Work and employment relations in a globalized world: the emerging texture of transnational labour regulation". Global Labour Journal, 4 (1): 26-47.

Ramalho, José Ricardo. (2005), "Novas conjunturas industriais e participação local em estratégias de desenvolvimento”. Dados, 48 (3): 491-524.

. (2014), "Trabalho, sindicato e globalização". Politica \& Trabalho, 41: 25-43.

Ramalho, José Ricardo et al. (2013), "Estratégias de desenvolvimento industrial e dinâmicas territoriais de contestação social e confronto político”. Sociologia \& Antropologia, 3 (5): 175-200.

Rombaldi, Maurício. (2016), "Diferentes ritmos da internacionalização sindical brasileira: uma análise dos setores metalúrgico e de telecomunicações". Caderno CRH, 29 (28): 535-551.

SAntos, Rodrigo Salles Pereira dos. (2011), "Redes de produção globais (RPGs): contribuições conceituais para a pesquisa em ciências sociais”. Revista Pós Ciências Sociais, 8 (15): 127-142.

SELWYN, Ben. (2013), "Social upgrading and labour in global production networks: a critique and an alternative conception”. Competition \& Change, 17 (1): 75-90.

TARrow, Sidney. (2009), O poder em movimento: movimentos sociais e confronto político. Petrópolis, Vozes.

Weber, Max. (2006), A “objetividade” do conhecimento nas ciências sociais. São Paulo, Ática.

Webster, Edward. (2010), "From critical sociology to combat sport? A response to Michael Burawoy's 'From Polanyi to Pollyanna: the false optimism of global labour studies'. Global Labour Journal, 1 (3): 384-387. 


\section{Resumo}

Trabalho e ação sindical em redes globais de produção

$\mathrm{O}$ artigo pretende fazer um balanço da incorporação do trabalho e da ação coletiva sindical à abordagem das redes globais de produção (RGPS) e de seus limites e potencial para o desenvolvimento de uma concepção sociológica multiagente e multiescalar do mundo do trabalho. Partindo da organização em rede das estratégias corporativas e seus impactos sobre as condições e relações de trabalho, a intenção é aprofundar o entendimento: (1) da conformação de redes laborais dispersas geograficamente, embora funcionalmente integradas; (2) do impacto destas sobre as formas de agência individual de trabalhadores, em suas variadas segmentações etária, étnica, de gênero e geográfica; e (3) das restrições e oportunidades à emergência de formas de ação e poder coletivo transnacionais condicionantes da agência econômica e política e influentes sobre a forma concreta dessas redes.

Palavras-chaves: Redes globais de produção (RGPS); Agência; Trabalho; Sindicato; Poder coletivo.

\section{Abstract}

\section{Labour and trade union action in global production networks}

In this paper, we aim to review the incorporation of labor, union and collective action into the global production networks (GPNs) approach, highlighting their limits and potential for developing a multi-actor and multi-scale, sociological conception of labor. From the network-based corporate strategies and their impacts on industrial relations and working conditions, the discussion argues for a deeper understanding of: (1) the formation of geographically dispersed, however functionally integrated, labor networks; (2) their impact on workers' individual agency according to their variegated age, ethnic, gender and geographic segmentations; and (3) the constraints and opportunities for the emergence of transnational forms of collective action and power, in order to affect the economic and political agency, and the concrete shape of these networks. Keywords: Global production networks (GPNs); Agency; Labor; Trade union; Collective power.

Texto recebido em 19/9/2017 e aprovado em 20/10/2017. DoI: 10.11606/0103-2070. ts.2018.138078.

José Ricardo Ramalho é professor do Departamento de Sociologia e Programa de Pós-graduação em Sociologia e Antropologia (PPGSA) da Universidade Federal do Rio de Janeiro (PPGSA-UFRJ).E-mail: j.ramalho@ifcs.ufrj.br. Rodrigo SAlles Pereira dos Santos é professor do Departamento de Sociologia e Programa de Pós-graduação em Sociologia e Antropologia (PPGSA) da Universidade Federal do Rio de Janeiro (PPGSA-UFRJ). E-mail: santosrodrigosp@gmail.com. 